\title{
Information society and civil society: Non-governmental organizations and computer-mediated communication in Latin America
}

\author{
Ricardo Gómez \\ 510 Landreville, ap. $B$ \\ Verdun, Quebec, H3E $1 B 4$ Canada \\ Tel/fax: +15147686805 \\ Email: gomezr@total.net
}

\begin{abstract}
The globalization of information and communication poses new challenges to this emerging civil society, as it provides new risks of censorship and control, but at the same time offers new opportunities for global networking and collective action. There seems to be very little research on the ways non-government organizations (NGOs) are confronting the information society and its effects. This paper explores current issues on computer-mediated communication (CMC) and virtual communities, and describes the preliminary findings of ongoing research of CMC uses in NGOs in Latin America. These findings suggest that an enhanced sense of belonging to a global civil society may be a positive effect of current uses of CMC by NGOs in the region.
\end{abstract}

\section{THE PROMISED LAND OF THE INFORMATION SOCIETY}

The information society has been acclaimed as an instrument for democracy, for postmodernity, and for control. It has been presented as the opportunity for every individual to communicate with the rest of the world and to bring about participatory democracy (Gore, 1996; Miles, Rush, Turner and Bessant, 1988; NTIA, 1993), and as the opportunity for the state or the market to control every individual (Poster, 1995; Rheingold, 1993; Sparks, 1994; Splichal, 1994) and constitute a police state in a global hypermarket (Proulx and Senecal, 1995). At 
the same time, it has been held responsible for the shattering of the grand narratives of progress and modernization, and the reconstitution of the public sphere as a fractal image of postmodern identities (Poster, 1995; Turkle, 1995; Vattimo, 1992). Nonetheless, there is increasing evidence that neither the happiest dreams nor the worst nightmares that have been proclaimed for the information society have been realized. Furthermore, I share Pierre Lévy's optimism when he claims that technological changes that upset the former balance of power and paradigms introduce the possibility of unprecedented changes and of new alliances and strategies (Lévy, 1990). Change is at the same time a risk, a challenge, and an opportunity. In the face of the globalized new world of the information society, what can be the role of civil society which is vital to the construction of genuine democracy?

Computer-mediated communication (CMC) is at the root of emergent practices in the information society. Among other things, CMC has introduced a new form of social organization between people who share an interest and not necessarily a territory or a cultural identity. Virtual communities are 'social aggregations that emerge form the Net where enough people carry on those public discussions long enough, with sufficient human feeling, to form webs of personal relationships in cyberspace' (Rheingold, 1993, p.5). Growing use of CMC has generated new forms of virtual communities (Jones, 1995a) or networlds (Harasim, 1994), established as places for social exchange, education or work. The growing process of the commercialization of the Internet has added a fourth networld, the virtual supermarket.

The possibility of creating and sustaining these virtual communities or networlds has been analyzed from different perspectives. Jones suggests that, through them, new opportunities emerge for education and learning, for the establishment of counter-cultures, for the restructuring of human-machine interaction, and for the revitalization of participatory democracy (Jones, 1995a). Are these claims any different from the euphoria accompanying the Global Information Infrastructure (GII)? Rheingold points out that 'the political significance of CMC lies in its capacity to challenge the existing political hierarchy's monopoly on powerful communication media, and perhaps thus revitalize citizen-based democracy' (Rheingold, 1993, p.14). Splichal is more cautious when he says that the nature of civil society, as well as that of the state and the economy, is 'decisively affected' by recent technological developments in computer-mediated communication; his optimism stops with the recognition that organizational changes in the economy, the state and civil society are possible and that, based on the experience of eastern and central European countries, total state control or repression is no longer possible, although it may still happen locally and temporarily (Splichal, 1994).

What is the direction of this effect? How will each sector appropriate the new tools and uses? In fact, how are these tools socialized?

\section{THE CONSTITUTION OF VIRTUAL COMMUNITIES}

Harasim insists it is not the CMC tools themselves but their use that is important in the constitution of networks into networlds. For this process to happen, a 
purpose, a place, and a population are required. Networlds or virtual communities are not constituted from technological tools if there is not a common purpose, an agenda, a timeline, which is then pursued in a place, one that can be a virtual cafe, classroom or commons, by a set of participants whose roles are clearly agreed (Harasim, 1994). Swerdlow insists that when people are already familiar with each other, what he calls 'the power of skin', then the opportunity is created to continue through electronic relations (Swerdlow, 1995). But Jones does not seem to be bothered by the need for familiarity or even of information exchange; he goes even further to say that virtual communities are bound not by transmission of information but by ritual sharing (Jones, 1995a). Ritual sharing in a virtual community can lead to all sorts of practices, such as the multiplication of identities and construction of cyberworlds in Multi-User Domains (MUDs), explored at length by Sherry Turkle. She points out that virtual reality can be seen as another reality, not necessarily in competition with real life; the boundary between virtual and real is fuzzy and, in that boundary, new cultural symbols and meanings can emerge. She points out that real life 'is just one more window', and not necessarily the best one (Turkle, 1995).

What is it then that fosters the interest in using CMC to constitute virtual communities of interest, networlds in which social, educational, commercial or democratic values can be ritually exchanged?

Virtual communities have been studied among computer-game players (Freidman, 1995; Fuller and Jenkins, 1995), MUD users (Turkle, 1995), and Usenet participants (Baym, 1995; MacKinnon, 1995; McLaughlin, Osborne and Smith, 1995). Many of these studies detail how the community is constituted through shared interests and practices, establishing roles and rules of conduct, and generating a virtual reality (VR) with varying degrees of connection with real life (RL). Sherry Turkle presents three different scenarios illustrating the effects of the move towards virtuality. She calls the first the Disneyland effect, in which denatured and artificial experiences seem real. The second is the artificial crocodile effect, when both the fake and the simulated realities seem more compelling than the real, thus devaluing the world of direct, unmediated experience. The third is the effect by which a virtual experience may be so compelling that we believe we have achieved more than we actually have. She concludes that, rather than making virtuality and real life compete, we will need to figure out ways in which we can get the best of both (Turkle, 1995).

The effects of introducing CMC, especially electronic mail, have been well documented in businesses, education and research. Rheingold suggests that CMC has the potential to change society at three levels: among individual human beings, in person-to-person interaction, and at the political level, especially if there is a strong community of users among citizens (Rheingold, 1993). Sproull and Kiesler (1991) have studied the effects of CMC in networked organizations. They differentiate two levels of effects of CMC: the first level is easier to anticipate, and includes the anticipated technical changes related to planned efficiency gains, cost displacements and added value, resulting from the introduction of $\mathrm{CMC}$ in organizations. Second-level changes (in which people start to change the ways they spend their time and value what is important, shifting social patterns, and the interdependence between members of the group) are generally slow and unanticipated, and are not necessarily caused by the technologies alone but rather 
are shaped by the interactions and uses the community gives to them. These findings seem to be confirmed by other more recent studies in organizations, cooperative research, and education, including the fact that most of the social or second-level changes are unintended and unanticipated. Management tends to focus on productivity and efficiency gains but there is a consistently reported gain in organizational commitment, solidarity, participatory and egalitarian decisionmaking, and better decisions being reached (Garton and Wellman, 1994; JohnsonLenz and Johnson-Lenz, 1994; Kaye, 1992; Rice and Steinfeld, 1994; Valacich, Paranka, George, and Nunamaker, 1993). Furthermore, there seems to be agreement in that the way CMC is used is more important than its frequency.

\section{TOWARDS A VIRTUAL CIVIL SOCIETY?}

Nonetheless, there is extremely little literature describing or analyzing concrete uses and meanings of CMC in virtual communities as part of civil society, although there is much debate and speculation about its possibilities. We are living in a time in which new forms of relationships and interactions are possible. This presents many risks, and many opportunities. We face new technologies that allow decentralized, multimedia, hypertextual, elastic, and interactive communication in a context of familiarity, ease of use, and instant feedback at a global scale. While the state and the market, both nationally and globally, have many privileges and advantages in accessing and using these technologies for hegemony, profit and control, civil society has also a role to play in using, understanding, and shaping the new media, and appropriating them for the democratic process. We are facing an opportunity for the 'transnationalization of civil participation', as Thorup puts it (in Frederick, 1992); there are increasing indications of an ongoing globalization from below, as opposed to the dominant globalization from above that has been so heavily criticized by Hamelink (1995). For Mark Poster (1995), a new dialogue is possible that configures subjects in a differentiated cosmopolitanism, far removed from the homogeneous massification resulting from the new communication technologies that has been feared or extolled for so long.

Transnational civil participation for a differentiated cosmopolitanism in a process of globalization from below, such is the promise of $\mathrm{CMC}$ for development and democracy. But more research is needed in order to overcome the idealization of the new uses of this new technology. Otherwise, we can repeat the uncritical analyses of experiences using radio and video, but this time joining with $\mathrm{Al}$ Gore's euphoric claims of the GII as a metaphor for democracy.

The process of globalization from below is not a new idea, but it is an emergent process that has only recently begun to be shaped and formed. Networks are popular and non-governmental organizations (NGOs) are important new actors in the international scene; they have been slowly gaining recognition and space in forums and decision spaces for global affairs. Although civil society is not a homogeneous group pursuing common aims, and NGOs are not its sole members, the blooming NGO movement throughout the world constitutes a new actor on the national and international scene. NGOs are becoming increasingly important actors both in their own societies and internationally. As Harris suggests, their challenge 
may be to come up with communication strategies that 'recognize and address the vastly changed international politico-economic scenario in which the negative consequences of financial monopolies, environmental degradation and unsustainable development are increasingly being felt in the so-called developed countries of the North' (Harris, 1996, p.8).

It has been shown how communication technologies such as radio, video and desktop publishing have been appropriated as democratic tools (Girard, 1993; Thede and Ambrosi, 1991). These technologies have allowed a decentralization of communication resources and helped to break down hierarchies of power. 'For the first time in history, progressive forces have access to communication tools previously reserved to corporations and the military' (Frederick, 1992, p.22). In the same way, the recent emergence of computer-mediated communication has played an important role in the revitalization of the civil society. As Frederick puts it:

'a global civil society is best seen in the worldwide movement of NGO and citizens advocacy groups uniting to challenge problems that are substantially different in scope and character from any that have faced the world before. Problems such as the proliferation of nuclear weapons, imbalanced resource use, hunger and poverty, the destruction of the rain forests, and the developing greenhouse effect are so large in scope and have such geographically dispersed effects that they confound local—even national—solutions' (Frederick, 1992, p.219).

\section{NGOs AND THE GLOBAL CIVIL SOCIETY}

NGOs had generally been very isolated from each other, but there has been a recent trend towards their articulation around some of these global issues. They are becoming increasingly visible at United Nations (UN) and other international forums as their power and capacity to communicate and coordinate actions increases. The 1992 Earth Summit in Rio de Janeiro is frequently regarded as a landmark, a turning point in the emergence of the global civil society (Afonso, 1996; Preston, 1994). The Earth Summit provided for the first time a meeting place in which world affairs were debated with a large participation of civil society. There were 100 heads of state and 178 nations represented, and a total of 35,000 people attended, the largest meeting of this kind ever. But most significantly, over one thousand NGOs registered at the conference, with about one third of them from the third world. At the parallel NGO summit that took place simultaneously with the UN meeting, over 9,000 organizations took part; this was the largest face-toface forum for NGO representatives from all around the world in a meeting of this kind (Preston, 1994).

Not only was the attendance by NGO representatives unprecedented, but an open electronic communication system was put in place by the Association for Progressive Communications (APC), providing email, international electronic conferences, and access to databases related with the UN Earth Summit. In this way, issues that were being discussed at the Summit and at the NGO meeting were available for consultation both on-site and internationally, via the APC electronic communication network ${ }^{1}$. After the Rio Summit, APC has provided similar communication services at other major international conferences: the World Human 
Rights Conference in Vienna (1993), the Conferences on Population and Development in Cairo (1994) and on Women and Development in Beijing (1995), and the Social Summit in Copenhagen (1995). The impact of this participation still remains to be further evaluated but, as Afonso states, it is now clear that on the international political scene 'the APC network now plays a key role, and constitutes an indispensable media to keep track of the experiences of civil society throughout the world' (Afonso, 1996, p.152).

While it may be true that NGOs worldwide have gained access to the lanes of the information society via the APC Network services among others, much remains to be accomplished in terms of global practices towards democratic communication. We need to focus on the more concrete aspects of NGOs' use of $\mathrm{CMC}$, and of electronic mail in particular since, of all the CMC tools, electronic mail remains the most readily available and used by NGOs. This is true especially in Latin America, where the APC nodes have until very recently offered exclusively line-driven, text-based connections to the network, providing access to email and electronic conferences. Until the end of 1995, it was not very easy for NGOs to get Internet access in most countries that had it, and the APC was the only alternative they had to use email (NGLS, 1995).

Nonetheless, email has been shown to be powerful enough to enact the 'ritual sharing' that constitutes virtual communities. What is yet to be seen is the actual use of these technologies, limited as they may seem, by the people in the NGOs involved. Most of the literature on the effects of CMC focuses on business, education or recreational virtual communities, and there is no guarantee that the same kind of effects hold when the users are NGOs in the construction of a virtual community for a global civil society. Moreover, there is only little evidence that the increased use of CMC by the NGO community has in fact helped to promote such a global civil society, or that it has had a positive impact on the democratization process as a whole.

\section{EMERGING PRACTICES IN LATIN AMERICA}

An ongoing study in Latin America ${ }^{2}$ shows that there are four main kinds of perceived effects of using CMC in NGOs: speed of communication, enhanced networking, better information, and reduced cost. Furthermore, there is a growing awareness of the possibilities offered by CMC to strengthen the coordination between diverse actors in civil society in a global field of action. I will briefly discuss some of the emerging findings of this study, which may help us to understand the actual uses and perceptions of CMC among NGOs in a Latin American country.

The speed of communication is, for obvious reasons, the most frequently mentioned effect of the use of CMC, and needs not be described in detail here; it is one of the self-evident first-level effects described by Sproull and Kiesler (1991), as discussed before. But second-level effects are not far behind in the perceptions of users, most of whom report a sense of enhanced networking with $\mathrm{CMC}$, which has allowed them a better coordination of activities based on shared interests with partners in the same country and around the world. Persons and institutions with common interests are perceived to be more easily brought together, independently 
of where they are located; the perception of a global scope of action is more easily achieved. Furthermore, initial data indicates that new contacts have been made possible for NGOs, providing more new partners with whom to exchange information. Users also report that $\mathrm{CMC}$ makes it possible to maintain the relations with their partners on a more regular basis, shortening geographical distances, and strengthening internal communication between branches of an organization, both nationally and internationally. Finally, some NGOs point out relationships with funding agencies have also been improved with the use of CMC.

In this way, $C M C$ is perceived to strengthen the bonds within the NGO community both nationally and internationally. This is materialized in an increased sense of knowledge and understanding of what others are doing, and better chances of exchanging information with those who share common particular interests. Communication with them is perceived to be more frank, direct, and continuous, allowing faster decisions and timely solutions, and encouraging 'joint efforts and proposals among a community of interests that is more tightly bound'. As one respondent puts it, $\mathrm{CMC}$ 'has helped me understand the day to day activities of the diverse and sometimes disperse action of NGOs, and also how deeply involved they all are in the process of construction of a (better) society.'

This perception has also expanded the geographical boundaries of partnerships to a larger perspective of a global NGO community confronting similar problems in different contexts. 'We have enlarged our frame of action and learned to conceptualize the problems from a global perspective,' points out one respondent; the possibility of embracing a 'solidarity without borders' is explicit or implied in a number of statements in the survey. Nonetheless, this perception of a global perspective is only a slow, continuous process. As one respondent comments, 'electronic mail is something that NGOs will need to be able to handle because in the long run this will allow them to have a global network of NGOs and carry out joint activities.'

The idea that the service provider provides a virtual meeting place for NGOs in the country is the most commonly reported reason to choose it among other commercial service providers. The APC node is perceived to group progressive, national NGOs; its non-commercial, alternative, and progressive character is a strong element of attraction for NGOs to join it, as well as the fact that it was established and promoted by a coalition of well-known NGOs in the country. The sense of belonging to an alternative family of NGOs in an alternative network for $\mathrm{CMC}$, both at national and international levels, is strongly present. As one respondent candidly explains, 'it groups all of us alternative people.' All these perceptions share the sense of belonging to a common group, a virtual NGO community that exists and that is further bound together through a sort of ritual sharing in order to become stronger as a consequence of using CMC.

It is important to note that even though solidarity, support, and a sense of community may indeed be strengthened with partners who are accessible though email, the relationships with those who are not connected can deteriorate. In fact, as some point out, many NGOs or other partners are not currently using or cannot afford this kind of communication, and are thus excluded from these networks. Increased access to CMC resources may limit this exclusion.

In sum, there is a generalized perception that CMC has at least positively affected the relations between NGOs and its partners, as it has allowed 'a slow 
tightening of the ties (among NGOs) with information about common interests and projects.' It is perceived to be 'an excellent way to speed communications to organize meetings and other international events, to prepare joint proposals, publications and other documents collectively or in co-authorship.' Furthermore, it has contributed to strengthening the sense of belonging to a global community, sharing many interests, concerns and activities; in order to reduce the exclusion of partners from the enhanced networking possibilities of $\mathrm{CMC}$, access to its resources has to be more widespread and available, even to grassroots and community organizations.

Better information is perceived to be another major effect of using CMC among NGOs. This means having access to more abundant, more updated and more relevant information, accessible through more channels and from more sources, and with more powerful tools to search and gather new information. Furthermore, information is also better since it is easily two-way, making feedback more fluid. In the words of one of the respondents, CMC 'has allowed us to be informed about important issues, and to express our opinions on them.'

Low cost of communication is the last major recurrent issue that is reported in relation to the use of CMC. Almost half of the respondents perceive that with $\mathrm{CMC}$ their communication costs are lower than they would be with other media. Some note that reduced costs are not only a matter of lower phone bills, but also reduced use of paper, envelopes and other office supplies, and less time spent on the task. Nonetheless, only a few respondents claim the need to cut costs as a reason to start using CMC in the first place, although the second most common reason to choose the APC node as service provider was the affordability of its services, especially when if first began to provide them. Several respondents point out that the APC node was the first to offer affordable services for the NGO community in the country even if, for some of them, this meant expensive long distance calls to the capital city. Nonetheless, this situation has changed so that comparable or better service is offered commercially; but it is not clear to what extent lower fees would cause any particular NGOs to seek a commercial service provider.

On the other hand, the need for more training and for more upgraded equipment is the most commonly expressed means of improving the NGOs' use of CMC. Lack of funds to pay for such items is reported to be of concern among several of them. Moreover, one respondent points out that electronic communication requires access to the only computer the institution has, and it is always in use for many other tasks. In this way, cost reduction may not be immediate but may be long term, because CMC 'requires a large initial investment, not only in technology but in training and support in order to be able to make daily use of the system.' Therefore, users are aware that there are many NGOs which cannot afford to start using $\mathrm{CMC}$ at this point, with the consequences described above.

Negative effects are barely mentioned by those who are already using CMC. However, these include the increased work pressure brought about by more information and by the exclusion of partners outside the electronic reach of the strengthening of networks. The lack of privacy and security in communications, and the predominance of the English language in CMC at an international level, are also perceived as limitations. On the other hand, some NGOs mention the poor phone and telecommunications infrastructure as barriers that limit their use of 
$\mathrm{CMC}$, especially in remote regions of the country, where the phone service is unreliable or non-existent.

\section{PREFERRED PARTNERS: TOWARDS A GLOBAL CIVIL SOCIETY?}

According to the data collected in this study, the preferred partners for communication exchanges among Latin American NGOs using CMC are groups and institutions with shared interests, concerns or activities. These are mainly other NGOs, both in the country and internationally, but occasionally they can include other networks, associations, universities, press agencies, international and bilateral organizations, and even government agencies. The most salient characteristic of the communication partners is their variety within a shared community of interests; other features seem to be secondary. As one respondent notes, they communicate "with very many organizations and institutions, of all kinds', but most respondents go on to define their preference for those who share their own field of expertise, concern or intervention, be it the environment, human rights, women, popular communication, housing, sustainable agriculture, or grassroots development, among others.

A small proportion of respondents also emphasizes the importance of establishing communication with universities and research institutes, some with particular stress on their libraries, databases, and education programmes. Even though the focus of these contacts is still the area of specialty or intervention of each particular case, hinting the same community of interest I have just described, it is noteworthy that these partners are sought to acquire valuable information for education, training, and research.

Despite the apparent heterogeneity in communication partners and counterparts reported, a common thread is implied in all of them. They represent organizations and institutions of civil society, brought together into communities of interest, exchanging information and strengthening linkages and networks in a global scope of action. As one respondent points out, 'there should be more communication and exchange of information with those who are in other countries and with different networks ... in order to strengthen the organization of civil society.'

There are only a few explicit mentions of the notion of civil society in the respondents' comments, but the implied message is palpable in at least half of them. NGOs appear to be using CMC slowly to enlarge the scope and strengthen the bonds between different sectors of civil society. These could be the first steps towards the transnationalization of civil participation, the differentiated cosmopolitanism that is made possible with the use of CMC among NGOs worldwide.

Further research on these issues is still needed if we are to understand the scope of the contribution of CMC to the strengthening of a global civil society. 


\section{REFERENCES}

Alfonso, C. (1996). Electronic Networks and Political Action at the Service of Civil Society. In A. His (Ed.), Communication and multimedia for people Paris: Transversales Science/Culture, (pp. 148152).

Baym, N. (1995). The Emergence of Community in Computer-Mediated Communication. In S. G. Jones (Ed.), CyberSociety: Computer-mediated communication and community, Thousand Oaks, CA: Sage (pp. 138-163).

Frederick, H. (1992). Computer-Communications in Cross-Border Coalition-Building: North American NGO Networking against NAFTA. Gazette (50), 217-241.

Friedman, T. (1995). Making sense of software: Computer games and interactive textuality. In S. G. Jones (Ed.), CyberSociety, op. cit. (pp. 73-89).

Fuller, M., \& Jenkins, H. (1995). Nintendo and New World Travel Writing. In S. G. Jones (Ed.), CyberSociety, op. cit., (pp. 57-72).

Garton, L., \& Wellman, B. (1994). Social Impacts of Electronic Mail in Organizations. Communication Yearbook, 18, 434-453.

Girard, B. (Ed.). (1993). La Passion Radio. Paris, Montreal: FPH, AMARC.

Gore, A. (1996). Global Information Infrastructure - GII Delivery at the International Telecommunications Union Conference in Buenos Aires, March 21, 1994. In A. His (Ed.), Communication and multimedia for people, op.cit., (pp. 69-77).

Hamelink, C. (1995). The democratic ideal and its enemies. In P. Lee (Ed.), The Democratization of Communication Cardiff, UK: WACC, University of Wales Press, (pp. 15-37).

Harasim, L. (1994). Networlds: Networks as social space. In L. Harasim (Ed.), Global Networks: Computers and International Communication, Cambridge, MA: MIT Press, (pp. 15-34).

Harris, P. (1996). Globalisation, civil society and communication. Media Development, 43(3), 8-9.

Johnson-Lenz, P., \& Johnson-Lenz, T. (1994). Groupware for a small planet. In P. Lloyd (Ed.), Groupware for the 21st. century: Computer supported cooperative working toward the millennium, London: Adamantine, (pp. 269-285).

Jones, S. G. (1995). Understanding Community in the Information Age. In S. G. Jones (Ed.), CyberSociety: Computer-mediated communication and community, Thousand Oaks, CA: Sage (pp. 10-35).

Kaye, A. (1992). Computer conferencing and mass distance education. In M. Waggoner (Ed.), Empowering Networks: Using computer conferencing in education. Englewood Cliffs, NJ: Educational Technology.

Lévy, P. (1990). Les technologies de l'intelligence. Paris: La Decouverte.

MacKinnon, R. (1995). Searching for the Leviathan in Usenet. In S. G. Jones (Ed.), CyberSociety, op. cit., (pp. 112-137).

McLaughlin, M., Osborne, K., \& Smith, C. (1995). Standards of Conduct on Usenet. In S. G. Jones (Ed.), CyberSociety, op. cit., (pp. 90-111).

Miles, I., Rush, H., Turner, K., \& Bessant, J. (1988). Information Horizons: The long-term implications of new information technologies. Brookfield, VT: Gower Pub.

NGLS. (1995). @t ease with e-mail: A handbook on using electronic mail for NGOs in developing countries. New York: United Nations Non-Governmental Liaison Service NGLS, Friedrich Ebert Foundation.

NTIA. (1993). The National Information Infrastructure -NII: Agenda for Action. In A. His (Ed.), Communication and multimedia for people, op.cit., (pp. 50-68).

Poster, M. (1995). The Second Media Age. Cambridge: Polity Press.

Preston, S. (1994). Electronic Global Networking and the NGO movement: the 1992 Rio Summit and Beyond. Swords \& Ploughshares: A Chronicle of International Affairs, 3(2), online at gopher.american.edu.

Proulx, S., \& Senecal, M. (1995). Is Technical Interactivity a mere pretense of Social Interaction and Democracy? Technologies de l'information et société, 7(2), 131-145.

Rheingold, H. (1993). The Virtual Community: Homesteading on the electronic frontier. New York: Harper-Collins.

Rice, R., \& Steinfield, C. (1994). New forms of organisational communication via electronic mail and voice messaging. In J. Adrianson \& R. Roe (Eds.), Telematics and Work, Hillsdale, NJ: Lawrence Erlbaum, (pp. 109-137). 
Ruth, S., \& Ronkin, R. (1992, ). Aiming for the elusive payoff of user networks: an NGO perspective. Paper presented at the annual meeting of the International Society for the Systems Sciences, July 1992, Denver, CO.

Sparks, C. (1994). Civil Society and Information Society as Guarantors of Progress. In S. Splichal, A. Calabrese, \& C. Sparks (Eds.), Information Society and Civil Society, West Lafayette, IN: Purdue University Press, (pp. 21-49)..

Splichal, S. (1994). From Civil Society to Information Society? In S. Splichal, A. Calabrese, \& C. Sparks (Eds.), Information Society and Civil Society, op.cit., (pp. 50-77).

Sproull, L., \& Kiesler, S. (1991). Connections: New ways of working in the networked organization. Cambridge, MA: MIT Press.

Swerdlow, J. (1995). Information Revolution. National Geographic Magazine, 188(4), 5-37.

Thede, N., \& Ambrosi, A. (Eds.). (1991). Video the Changing World. Montreal: Black Rose Books.

Turkle, S. (1995). Life on the Screen: Identity in the age of the Internet. New York: Simon \& Schuster.

Valacich, J., Paranka, D., George, J., \& Nunamaker, J. (1993). Communication concurrency and the new media. Communication Research, 20, 249-276.

Vattimo, G. (1992). The Transparent Society. Baltimore: Johns Hopkins University Press.

1 The APC is probably the most often cited case of CMC use for democratization of communication, but it is by no means the only one. The work of the Electronic Frontier Foundation and of Computers for Social Responsibility are frequently mentioned, and the proliferation of local public-access freenets in many cities in North America have made major contributions to democratizing cyberspace. Their reach is, nonetheless, far more localized and has had less impact on the global arena than the APC.

2 This study is part of the author's dissertation research. The findings reported here are based on a survey administered to all NGOs affiliated with an APC service provider in a Latin American country, and on follow-up in-depth interviews with some of the respondents. 